\title{
IS THE WHOQOL-BREF INSTRUMENT RELIABLE FOR MEASURING THE QUALITY OF LIFE HEALTH DURING THE COVID-19 PANDEMIC?
}

\author{
Windy Mariane Virenia Wariki'), Cicilia Pali²), Muhammad Awaludin3) \\ 1)Department of Community Medicine, Faculty of Medicine \\ Universitas Sam Ratulangi, Manado, North Sulawesi \\ 2)Department of Psychology, Faculty of Medicine, Universitas Sam Ratulangi \\ Manado, North Sulawesi \\ 3)Department of Internal Medicine, Faculty of Medicine \\ Universitas Sam Ratulangi, Manado, North Sulawesi
}

\begin{abstract}
Background: The World Health Organization Quality of Life-BREF (WHOQoL-BREF) has been used worldwide as a valid and reliable instrument to measure the quality of life on various age groups and types of disease. However, there remained a lack of information about is validity and reliability when it is used in Indonesia during COVID-19 pandemic. This study aimed to assess the reliability of the WHOQoL-BREF questionnaire as a tool to measure the quality of health life during the COVID-19 pandemic in Indonesia.

Subjects and Method: This was a cross-sectional study conducted in Tomohon, North Sulawesi, from April to October 2021. A total of 434 subjects was selected by non-probability sampling. The WHOQoL-BREF was a 26-item scale in which items were answered in five-point responses, ranging from 1 to 5 . It contained four domains, including physical health (7 items), psychological health (6 items), social relationships (3 items), and environmental health ( 8 items). It also contained QOL and general health ( 2 items). The reliability data were analyzed by Pearson correlation and Cronbach alpha.

Results: The test instrument showed overall reliability of WHOQoL-BREF with high Cronbach alpha, including physical health, psychological health, social relationships, and environmental health, and general health domains $(\alpha=0.90 ; p<0.001)$

Conclusion: The WHOQoL-BREF shows overall reliability when it is used in Indonesia during the COVID-19 pandemic.
\end{abstract}

Keywords: quality of life, reliability, COVID-19, WHOQoL-BREF

\section{Correspondence:}

Windy Mariane Virenia Wariki. Department of Community Medicine, Faculty of Medicine Universitas Sam Ratulangi. Jl. Kampus Bahu, Manado, North Sulawesi. Email: wwariki@unsrat.ac.id. Mobile: +6282191436307 